\title{
The Ecology of Translation: A Case Study of Two Different Translations of Kanyasulkam in English
}

LAKSHMI HARIBANDI

\begin{abstract}
The interface between the translators and their ecological environment becomes vital in understanding the nature of the translation carried out and the final shape the target texts take. The translators' subjectivity can only be understood in relation to their context of production, circulation, and reception. It is therefore important in any product-oriented research to study the ecological environment of the translators and its influence on their decision-making process and the translation strategy that they adopt. The present paper is an attempt in that direction. It presents a case study of two different translations of a Telugu classical text, Kanyasulkam, in English. The study reveals how the overall context of translation becomes a major agency in conditioning the work of the translators and how it accounts for the divergence between the two translations of the text selected. It also brings to the fore a very interesting technique of translating a classical text from India by a transnational translator in an alien environment for the consumption of the distant other.
\end{abstract}

Keywords: Kanyasulkam, the Ecology of Translation, Translator Studies, Domestication, Foreignisation, Transnational, Contextualisation.

In any product-oriented descriptive study, apart from the text and the context, the agency involved in the translation, particularly that of the translators and publishers, becomes important as it is their field and habitus that play a major role in shaping the translation. In the context of Translation Studies taking a sociological turn, Bourdieu's theory of cultural field (1994) that emphasized the social conditions of production, 
circulation, and consumption of artistic works and his concepts of 'field' and 'habitus' (Bourdieu 1977), attained prominence and brought into fore new perspectives. The present paper attempts to demonstrate how the socio-personal and sociographical trajectory (Foglia 2014) of the translators and the environment where the translation project takes place would impinge on the translators' choices and decision-making process and thus account for the different treatment given to the same source text.

A classical text from Telugu and its two different translations in English that were made in different contexts have been selected for the present study. The text selected is a classical drama from colonial India, titled Kanyasulkam by Gurajada Apparao, first staged in 1892 and published in 1897. Its two translations considered for this study are a) Kanyasulkam by C. Vijaya Sree and T. Vijay Kumar, published in 2002 by Book Review Literary Trust and b) Girls for Sale by Velcheru Narayana Rao published in 2007 by Indiana University Press, Bloomington \& Indianapolis, USA. The purpose of this paper is not to judge the quality of one translation pitting it against the other. It is to understand the causal relations between the translation techniques/strategies adapted by the translators as inferred from the textual analysis of their translations and their ecology in general.

Andrew Chesterman in his article "The Name and Nature of Translator Studies" (2009) proposes the new term 'Translator Studies'. He states that "In Translator Studies, texts are secondary, the translators themselves are primary" (p.15). We can see from this title how he has played on the title of the path-breaking seminal article by James. S. Holmes. He altered 'Translation Studies' to 'Translator Studies' thus, shifting the focus from translation to the translators. This shift in focus led to different kinds of research questions coming to the fore like 
who is/are the translator(s). What is their socio-cultural, geographical, political, ideological, etc. background? Are they source language speakers or target language speakers? Are they national or transnational beings? Who are they collaborating with? Where are the translations published? Who are they translated for? What are the expectations of the readers? What is the experience of the translators? What are the habitus and the field of the translators concerned? What is their cultural/symbolic capital? Other research questions include the relationship between the habitus of the translators and the translation norms that exist in the given socio-cultural setting at the given time; the role models of the translators; their working conditions; the self-perception/image of the translators themselves; and the perception of the others towards them and their work; the position occupied by the translated literature in the target literary polysystem and the status of the translators' themselves; the role of the publishing houses concerned and so on.

According to Chesterman (2009), Translator Studies has three focal areas. While the cultural branch deals with the translators' Ideologies, ethics, history, etc., the cognitive branch deals with their mental processes, decision-making, the impact of emotions, attitudes to norms, personality, and so on. And the sociological branch deals with the translators' networks, institutions, status, workplace processes, etc. In short, in his mapping of the field of Translator Studies, Chesterman tries to cover all aspects related to cultural, cognitive, and social contexts and conditions of the translators and their overall ecological environment of translation.

In Translation Studies, comparative studies of the kind that involve the analysis of a source and a target text pair or a source text and its multiple translations within the same target language or across different languages are nothing new and 
have been in vogue for a long time. Though they yield very useful data regarding different interpretations of the text, different methods of translating depending on the skopos and the intended target audience, different approaches to translation quality assessment, and so on, they normally pay little attention to the role of the translator(s) involved. Even after Translation Studies took a cultural turn it was the sociology of the texts and the contexts that became important, not the translators. The notable exceptions are the work done by Andre Lefevere (1992) when he discusses the role of the patron and Gideon Toury (1995) with his work on descriptive Translation Studies and his concept of translation norms. These could be taken as the first steps towards Translation Studies taking a sociological turn. The major contribution of the sociological turn can perhaps be that of bringing the mediators, who have been hitherto neglected, to the forefront and making them central to the entire activity of translation.

This kind of translator-centredness (Hu Gengshen 2010) becomes an emerging new paradigm and a new pole in Translation Studies, in addition to the earlier two, sourcecentred and target-centred. It gained prominence in ecotranslatology and 'Ecological Translation Studies'- an emerging paradigm in Translation Studies that considers translation from ecological perspective (Hu Gengshen 2004). Though it was Michel Cronin (2003) who used the term "translation ecology" for the first time, it was the Chinese school of Translation Studies, mainly $\mathrm{Hu}$ Gengshen who advocated it through a series of publications.

According to $\mathrm{Hu}$ Gengshen, the ecological approach to Translation Studies "focuses on the wholeness of translation ecology, interprets the translation process from the perspective of the translation ecological environment, describes the relationship between the translator and the translation 
ecological environment" (2008: 1-5). The interrelationship between translation and its environment gets prominence in this approach. Eco-translatology is thus, an all-inclusive approach that considers the entire eco-system, the entire environment in which the translation takes place, and investigates the interrelationship/interdependencies between the translator and her/his environment. The present study selected this particular Telugu text and its two different translations in English since these translations were made in different contexts/ecological environments and thus account for the different treatment given to the same source text.

Let us now move on to the texts under consideration.

\section{Kanyasulkam (Here after Translation-1(TT-1))}

The first translation under consideration, Kanyasulkam was a translation into English by C. Vijayasree and T. Vijay Kumar who were professors of English at Osmania university, Hyderabad. It was translated locally and published in India mainly for domestic consumption, for non-Telugu Indian readers.

\section{Girls for Sale (Hereafter Translation-2 (TT-2))}

The second translation under consideration is by a transnational, Velcheru Narayana Rao, who was a professor at the University of Wisconsin-Madison, USA.

The title of this translation- Girls for Sale is a translation of the source title Kanyasulkam in English. It also has a subtitle 'Kanyasulkam, A Play from Colonial India'. This kind of double translation- both translating the title and also retaining the source title- reflects a general practice observed in the English translations of literary texts from Indian languages. However, the interesting point to be noted here is the added explanatory tag- A play from Colonial India. This tag can be 
understood as indicative of its being published outside India, for the consumption of a non-Indian audience.

The translator, as someone living in the USA, translated the work for the consumption of mainly his English (American) audience. The relation between the translator and his environment becomes a major factor that informs the translation process. As per the information given in the Acknowledgements, several friends of the translator, (mainly Indian-Americans and Americans) including David Shulman, who collaborated with him in several other translation projects as well, have also contributed to this translation by their comments and suggestions that helped the translator revise the draft several times. Further, the translator himself states that he worked on this translation for a long time, a couple of years, improvising his draft. It becomes evident from the closer examination of the micro aspects of translation that the translation has been revised mainly from the perspective of its readability to an English audience. This long journey of the translation process also explains why the translation is the way it is.

The details regarding the paratexts that accompanied these two translated texts are given in the Appendix, as the data provided by the paratexts is of immense help in both sociological and ecological studies of translation.

Let us consider the following illustrations in order to understand how the two translations differ from each other. The illustrations have been organised into five sections (a-e).

\section{A. The Translation of the English Words Used in the Source Text}

1. ST: నీ దగ్గర కాపర్స్ ఏమైనా ఉన్నాయా? నా దగ్గర కరన్సీ నోట్లున్నవి గాని మార్చలేదు 
Transliteration:

nii daggara kaapars eemainaa unnaayaa? naa daggara karencii nooTlunnavi gaani maarcaleedu.

TT-1: Have you any "coppers" on you? I have only "currency notes".

TT-2: Do you have any change in your pocket? I only have large bills. (Emphasis mine, unless otherwise stated)

As it can be observed from the above, the TT-1 retains the source words 'coppers' and 'currency notes' as it is the strategy that they have followed throughout the text. It enabled the translators to retain the alliteration present in the source text. The TT-2, on the other hand, does not always retain the English words used in the source text. In this case, we can observe that it makes use of the words/expressions of popular usage in contemporary English. The translation of 'currency notes' to 'large bills' indicates the context of its production and the intended audience. In fact, this expression could have been retained as it would be understood by the American audience.

\section{ST: కిస్ మిస్ సెలవులు}

\section{Transliteration:}

kismis selavulu

TT-1: Kismiss holidays

TT-2: the beginning of Christmas vacation

The usage of Kismiss, a corrupt form of 'Christmas' is very popular among the uneducated in the Telugu-speaking world. It might be the case with other Indians as well. While this has been retained in TT-1, TT-2 replaces it with its correct form. 
In fact, TT-1 retained all the English words employed in the source text as they are and puts them between single inverted commas. In cases where the English words appear in the source text in their corrupt or nativized forms, (e.g. 'kismiss' (Christmas), 'Inispikataru' (Inspector)), the correct forms of these are provided in the glossary given at the end. Besides the words that belong to other languages like Persian, Sanskrit and Arabic have also been retained in the translation and their meanings are also explained in the glossary.

The two different strategies adapted by these translators clearly reflect their context of production and intended audience.

\section{B. The Translation of Some Individual Words and Expressions}

3. ST: (జేబులోంచి చుట్ట తీసి పంటకొన కొరికి) పిల్లా, అగ్గిపుల్ల.

Transliteration:

(jeebuloonci cuTTa tiisi panTakona koriki) pilaa, aggipulla.

TT-1 (Takes out a cigar from his pocket, bites its end) Girl, A matchstick, please!

TT-2 (Takes a cigar, bites off its end) Give me a light, honey!

While TT-1 literally translates the source text, the TT-2 translates the word 'aggipulla' (matchstick) into 'a light' and the word 'pilla' (girl) into 'honey'. This act of translator in choosing to use the word 'honey', the term of endearment specific to Anglo-Saxon culture, results in the dislocation of the source culture. Clearly, this is an instance of domestication or cultural translation deliberately resorted to by the translator, perhaps to meet the demands of his target context. The rhyme present in the source text between Pilla (girl) and Aggipulla (match stick) is lost in both the translations. 


\section{ST: అతను చెప్పేదంతా తప్పుల తడక}

Transliteration:

atanu ceppedantaa tappula taDaka

TT-1: His teaching is all wrong.

TT-2: All that he teaches is a bunch of bullshit.

In this case, while the TT-1 paraphrases the original expression 'tappulataDaka', the TT-2 uses a slang-'bullshit' and tries to create an alliteration between 'bunch' and 'bullshit'. This is again a case of cultural translation involving the use of an American slang word.

This kind of translation might make the text read smooth for the target readers abroad, but the English readers at home would find it awkward or odd as it amounts to dislodging or uprooting the rural folk from their native soil and placing them in an alien land. In any case, it would be unfair to judge the translation from the perspective of the Indian readers of English at home as the context of production, consumption, and circulation of this translation is something else.

5. ST: నిలబడండి. కర్పూరం వెలిగించి మంగశహారతి పళ్ళెం తెస్తాను.

Transliteration:

nilabaDandi. Karpuuram veliginci mangalahaarati pallem testaanu.

TT-1: Wait! I'll light some Camphor and bring the arti plate.

TT-2: Wait, I'll bring a welcoming flame to auspiciously invite the new couple into the house.

As it can be observed, the TT-1 faithfully reproduces the source text, and retains the source term 'arti', since the translation is mainly meant for non-Telugu Indian audience 
who is familiar with these words and the custom that they refer to. The TT-2, on the other hand, opts for an explanatory translation. It also adds a footnote explaining the Indian custom of welcoming a newly married couple with Harathi, as the translation is meant for an English audience who are not expected to be familiar with the custom in the source culture. It is a cross-cultural translation in its true sense, as opposed to the translations produced in English in the Indian context, for the consumption of the fellow Indian readers, like the TT-1.

6. ST: నరులక్చద్దు-మా బోటి సిద్ధులకు, చలీ, వేడీ, సుఖం, ధుఖ్ఖం, యెక్కడివి?

Transliteration:

narulakkaddu-maabooTi siddhulaku, calii, veeDii, sukham, dhukkham, yekkaDivi?

TT-1: True, for humans. For siddhas like us, cold, heat, joy, and sorrow mean nothing.

TT-2: To ordinary mortals, it is. To siddhas like us, people of spiritual power, there are no such things as heat or cold, pleasure or pain.

While there is no explicitation of the word 'siddhas' in TT-1, in TT-2 we find the double translation, both retaining the word and also explicating it. This is indeed a standard practice followed by many translators when they retain the culturespecific terms or expressions of the source text that become unintelligible to the target audience.

\section{ST: యెర్రి గొల్లోభ్ళు}

Transliteration:

Yerri golloollu 


\section{TT-1: You foolish shepherds}

\section{TT-2: You morons}

While TT-1 is a literal translation of the source expression, TT-2 translated it into an informal 'morons'. This shift also falls in line with the overall translation strategy that the translator has followed as demanded by his cultural and social context of production and reception of the translation.

8. ST: అతగాడెవడు? వొల్లకాట్లో రావనాధాయ?

Transliteration:

atagaaDevaDu? vollakaaTlo raavanaadhaaya?

TT-1: Who is that 'he'? That anonymous fellow.

TT-2: Who is he anyway, Jack in the Jungle?

As it can be observed, while TT-1 paraphrased the source expression- 'vollakaaTlo raavanaadhaaya', TT-2 replaced it with its equivalent drawn from the target culture. The source expression is an expletive that has a literal meaning of 'Ramanadham in/of a graveyard'. This instance also makes clear the TT-2 translator's context/location and the intended readers.

9. ST: నీ ఇనుప చేత్తో యేస్తే, పొల్లు ముక్కలే పడతాయి; మంచి ముక్కలడతాయా? తధాస్తు!

Transliteration:

Nii inupaceettoo yeestee,pollu mukkalee paDataayi; manci mukkalaDataayaa? tadhaastu!

TT-1: If you deal with your iron hand, they'll only be useless cards. Thathastu! 
TT-2: Your leather hand only deals out junk cards, never good ones. May God make your words come true.

Here, while TT-1 retained the source expression, Thathastu (Sanskrit. meaning 'so be it') as it is an expression widely used in India, TT-2 translated its meaning for the benefit of its intended readers. Secondly, the TT-2 translated the source idiom- 'iron hand' as 'leather hand'. Actually, 'Iron hand' in Telugu means something different from what a 'leather hand' means in English. It is a jinx in Telugu.

10. ST: గేదె పెరుగు చమే, చేగోడి చమే

Transliteration:

Geede perugu camee, ceegooDi camee

TT-1: Buffalo curds chame, Chegodi chame

TT-2: Thick curds ca me, cookies ca me

11. ST: "కందిగుండా చమే, ఇంగువనూ చమే"

Transliteration:

"kandigunDaa camee, inguvanuu camee"

TT-1: "Chutney powder Chame, spicy powder Chame".

TT-2: "French fries ca me, Chocolate ca me".

Both TT-1 and TT-2 have provided an explanation for ' $\mathrm{Ca}$ me' in the glossary and the notes respectively (A mantra called Camaka often chanted in Brahminic rituals comprises a long list of things one wants God to provide them where each item in the list ends with a $c a$ ("and") and $m e$ ("to me")).

In both 10 and 11, one can observe how the names of the food items mentioned in the source text have been translated differently in the two translations. While TT-1, either retains or literally translates them into English, TT-2 replaces them by 
randomly chosen names of food items common to its context of production. This is a clear case of domestication or if we may call it, 'Americanization' or Anglicisation'. Incidentally, the original connotation, the reference to the favorite food items of the community of Brahmins in 11 above gets lost in both the translations.

\section{The Translation of Kinship Terms:}

12. ST: యేమివాయ్ బావా, యెడం దవడ యెర్రబారింది?

Transliteration:

yeemivaay baavaa, yeDam davaDa yerrabaarindi?

TT-1: What brother-in-law, why has your left cheek turned red?

TT-2: Why, my young man, your cheek looks bruised?

Firstly, we cannot ignore the alliteration present in the source text that makes it hilarious, but difficult to reproduce in any translation. Besides, while TT-1, as usual, faithfully translates the source sentence, TT-2 deviates from the source by translating the word 'baavaa', which literally means 'brotherin-law', as 'my young man'. The connotation implied in addressing someone as 'brother-in-law' is lost in this translation.

Similarly, the word, 'vadina' that literally means 'sister-inlaw' has also been translated in a similar fashion in the two translations. Consider the following:

13. ST: ఏం వదినా కంట నీరు పెడుతున్నావేం?

Transliteration:

Eem vadinaa kanTa niiru peDutunnaaveem?

TT-1: Why, sister-in-law why are you crying? 
TT-2: Why are you crying, young lady?

14. ST: చూశావూ, వొదినా! నీ తమ్ముడు చిన్న గుంటడయీ, అప్పుడే గొల్ల భామల్ని పట్టుకుంటున్నాడు.

Transliteration:

Cuusaavuu, vodinaa! Nii tammuDu cinna gunTaDayii, appuDee golla bhaamalni paTTukunTunnaaDu.

TT-1: Did you notice that, sister-in-law? Though he is still a child, your brother is already chasing butterflies!

TT-2: Honey, your brother is not a kid anymore, he is chasing after girls.

It can be observed from the above two instances $(13 \& 14)$ that the TT-1 faithfully translates the source term 'Vadina' as 'sister-in-law', but the TT-2 translates it as 'young lady' in one case and as 'Honey' in another case. This can be seen as an attempt to domesticate the text in order to suit the target audience.

The cultural significance of using an expression like 'brotherin-law' or 'sister-in-law' while addressing someone unrelated is lost in TT-2. But then this shift can be justified in terms of the readership as in any case an English audience may not be able to understand the implied meaning present in the original unless explained to them. They may, in fact, take it in its literal meaning indicating the kinship.

However, the TT-2 follows the practice of explaining in the notes given at the end the source socio-cultural aspects that it could not retain/communicate in the text. For instance, in one section of the endnote, it clearly explains the address system in Telugu, the use of honorific pronouns, and also the implied meaning of addressing someone as 'sister-in-law' or 'brotherin-law'. 
The following are the notes given in this regard:

a) Sister-in-law is a kinship term Girisam adopts to allow himself room for an erotic undertone in his conversations with her.

b) In Telugu kinship, relationships are broadly divided into joking and non-joking classes. Joking relationships are those where men and women could potentially flirt with each other. Father-in-law, mother-in-law, son-inlaw, brother-in-law, and sister-in-law are joking relationships. Mother, father, brother, and sister are nonjoking relationships.

Similarly, the word very commonly used in Telugu-ఛీ (chee), which has a wide range of meanings depending on the context, has always been retained in TT-1, but in TT-2, in many contexts, it is left out and in one instance it has been translated as 'Yuck'. This is also a case of domestication and these choices made by the translator reflect his translation environment.

Another point noticed in these translations is regarding how they maintain or change the interpersonal relations between some characters. While in Telugu by using a honourific pronoun or suffix one can express one's respect to the other person, in English since it does not have honourific pronouns, overtly we have to use the word 'Sir'.

For instance, Girisam is Venakatesam's tutor and thus the latter always uses an honourific form of address while speaking to Girisam. In this case, while TT-1 uses the word 'sir' at the end of almost every sentence spoken by Venkatesam to his teacher Girisam, the TT-2 hardly uses it. The TT-2 however provides a separate section on Kinship and Friendship in Telugu (p. 193-194). 


\section{The Translation of Verse}

Yet another interesting point of comparison between the two translations is related to the text that is given in verse form in the source text. While such text is faithfully translated into English without any deviation in TT-1, the TT-2 attempts to trans-create them making them more appealing poetically in English. This can be attributed to the fact that the translator of TT-2, is a poet himself and also has the rich experience of translating many poetical compositions from classical Telugu into English.

Consider the following:

15. ST: నీ సైటు నా డిలైటు;

$$
\begin{aligned}
& \text { నిన్ను మిన్న } \\
& \text { కానకున్న } \\
& \text { క్రైటు రెచడ్ ప్లైటు, } \\
& \text { మూను లేని నైటు. }
\end{aligned}
$$

Transliteration:

Nii saiTu naa dilaiTu;

Ninnu minna

Kaanakunna

kwaiTu recaD plaiTu, muunu leeni saiTu.

TT-1: Your 'sight' my 'delight'

If I don't see you

often enough

"Quite wretched plight 
Moonless night".

TT-2: Your sight

Is my delight

If I don't

Embrace you tight,

It's a sad plight

Like a moonless night.

Here two things can be observed. While TT-1 retains all the English words (sight, delight, quite, wretched, plight, Moon, night) used in the source text as they are and also the line arrangement; TT-2 changes the line- 'Quite wretched plight' into 'it's a sad plight' and the sentence 'if I don't see you' has been translated as 'If I don't embrace you tight', probably for the sake of rhyme. Secondly, TT-2 changes the arrangement of the lines and splits some lines into two, and maintains end rhyme. In short, while TT-1 translates the poem, the TT-2 trans-creates it.

Consider another example:

16. ST: పుల్లుమూను లైటటా

$$
\begin{aligned}
& \text { జాసమిన్ను వైటటా } \\
& \text { మూనుకన్న } \\
& \text { మొల్లకన్న } \\
& \text { నీదు మోము బ్రెటటా } \\
& \text { టా! టా! టా! }
\end{aligned}
$$

Transliteration:

Pullumuunu laiTaTaa 
Lakshmi Haribandi

Jasminnu vaiTaTaa

Muunu kanna

Molla kanna

Niidu moomu braiTaTaa

Taa! Taa! Taa!

TT-1: Full moon light-ta

Jasmine white-ta

More than the 'moon'

More than the jasmine,

Your face 'bright-ta'

ta! ta! ta!

TT-2: Full moon is light

Jasmine is white

forget the moon

forget the flower

your face is bright

brighter than bright

bright, bright, bright

Even in this case while TT-1 translates the source lines faithfully, TT-2 exercises some freedom and slightly modifies the source poem, especially the second half of the poem. This indeed results in a new poem based on the source poem.

E. The Translation of the Words Related to the Card Game Another interesting difference between these two translations is observed in Act 5, scene 2. Here, there is a card game being played at Madhuravani's place. Naturally, the conversation 
that takes place over there centres on the game being played. In this case too, while we find TT-1 simply translating the terms that referred to the game, the TT-2 either substitutes them by their equivalents drawn from the target culture or retains them and adds an explanation. In fact, TT-2 adds a 2-page note at the end explaining the card game (p. 197-198).

Consider the following:

17. ST: లాంతరేశావు. యేటెత్తవు? రొండు.

TT-1: Hopeless cards... What do I take? Two.

TT-2: You dealt me a Yarborough. What is there to pick up? Two.

(The notes given at the end for the word Yarborough is as follows: A Yarborough, called laantaru in Telugu, is a hand containing no cards higher than nine. So-called after Charles Anderson Worsely (1809-1987), $2^{\text {nd }}$ Early of Yarborough, who is said to have bet 1,000 to 1 that such a hand would not occur.)

Finally, let me add a note on the 'Notes' the TT-2 provides at the end, act-wise, page-wise that runs into 23 pages. These elaborate Notes given at the end (p.203-243) clearly indicate not only the skopos of the translator but also the context of the production, circulation, and consumption of the translation. While TT- 1 only gives a glossary, mainly of the source terms and expressions that are retained in the translation, the TT-2 provides elaborate notes. Most of the information given in 'Notes' is encyclopaedic in nature and is deemed necessary for the non-Indian audience to understand and appreciate the text the way it needs to be. Everything is explained in detail in a scholarly way, including the inter-textual references. The translator really deserves to be appreciated for this kind of meticulous work, and his knowledge of the classical literature 
in Sanskrit and the socio-cultural history of the land of the Telugu speaking people is unparalleled. The different kinds of information provided by the paratexts make this translation a perfect fit to be used as a textbook by any literature/ culture studies/ comparative literature department anywhere in the world. I wish the translators translating literary texts from foreign languages into Indian languages could follow a similar procedure providing all the socio-cultural information regarding the source text so that the readers would be in a position to appreciate the text better.

For instance, consider the note given for the word 'Saani'. While TT-1, being a glossary, only states 'Saani: A caste of dancers', the TT-2 gives the following text:

"Dancing girl" is another term for nautch-girl, a colonial English term (nautch from natya, Sanskrit, dance, via Hindi nac) that social reformers of Andhra used for women from a caste called Bogam-vallu, Sani-vallu, or Vetyas.

Bogam is a Telugu word derived from Sanskrit bhogam (pleasure/joy/luxury), and vetya is a Sanskrit word assimilated into Telugu. Nautch-girls were courtesans and were kept by upper-caste men as their pleasure-women.

Bogam women were well educated and highly cultured. Some of the greatest singers, dancers, and poets came from women of this caste. Bogam women served as court poets of the Nayaka kings of Tanjore and Madurai. Colonial moralists viewed these women as prostitutes, and the Andhra social leaders of the time adopted the same attitude toward them. A new name was invented to give respectability to them: devadasis, or servants of god, despite the facts that in Andhra, Bogam-vallu were mostly secular and did not have much to do with temples. In 1956, the government of Andhra Pradesh prohibited dancing by these women and moral activists forced them to reform themselves and live respectable lives... 
(Further, the next also has another half a page in this entry that presents the research that has been done on devadasis) (p. 203204).

\section{Concluding Remarks}

The present paper tries to underscore the role played by the geographical location of the translators and their publishers and their intended target readers in the decision-making process of the translator and in turn the overall textual makeup of the target text. In other words, this study attempts to bring to the fore the socio-cultural, and geographical context of the translation in terms of its production, circulation, and consumption, along with the profile of the translators that plays a major role in shaping the translation. The contextualisation of any act or instance of translation, from the start to finish, is required to have a comprehensive understanding of the translation process. The sociology of the translation along with the sociology of the translators needs to be considered in any product-oriented descriptive study. The ecology of translation is something that encompasses everything related to any act of translation. This kind of inclusive approach is necessary for any study of translation to have a global view.

The role of the human agency, particularly that of the translator, becomes very important in any translation, more so in literary translation. We can say that the shadow of the translator or the footprints of the translator is felt everywhere and $\mathrm{s} /$ he becomes certainly visible in every translation, though the degree to which s/he is visible might vary from case to case. The translator's habitus and the field play an important role in shaping the translation in addition to her/his skopos and the socio-cultural context of its production, circulation, and consumption. For instance, the TT-2 examined in this study gives more importance to the readability of the text in English 
rather than its fidelity to the elements of the source text at the micro-level going by the demands of its context of production and consumption, but nonetheless provides all the background cultural information in the form of different paratexts that have been added to the text. This is indeed a new technique of translation, a kind of balancing act that tries to do justice to both the source text/culture and the target readers at the same time. Further, this technique makes the target text read smoothly and fluently. The translator being the native speaker of the source language tries to serve it by translating it into English and being a transnational living in the United States attempts to meet the demands of his context. The translation process that went into the making of this text can be understood only when we pay attention to the bio-details of the translator and the way he executed his translation project, including the people who assisted/collaborated with him. One cannot but agree with Hu Gengshen (2010) when he proposes "translation as adaptation and selection".

When we analyse the translation, comparing it with the source text and the other translation under consideration, we find many instances of cultural translation/adaptation /domestication. The translation, on the whole, seems to serve the twin purposes in-one-go to present a readable/smooth text to an English audience and at the same time provide all the contextual and cultural information regarding the source text in the form of paratexts for the benefit of those interested in a detailed ethnographic study of the text. This can indeed be considered a new technique of translating that makes the main text embedded in a plethora of paratexts that help introduce the source text and its cultural, social, and literary context to the culturally distant target audience. The translator thus tries to balance the requirements of his target audience and his desire to preserve the socio-cultural ethos of his native language and culture. The nature of domestication in translation also 
depends on whether the translator is a native speaker of the source language or the target language, though originally the term domestication as it is employed by Venuti (1995) referred to the translation of a foreign text into the dominant native language by the native speaker of the target language.

Further, in a case like the present one, we do not have to consider the asymmetrical power equation between the source and the target language/culture and its role in informing/influencing the translation process as it is done in cultural approaches to Translation Studies since the translator is a member of the source language and culture and his attempt is to serve his native literature by translating it into an international language, English.

The field of investigation in Translation Studies is becoming more and more complex and began to encompass almost every area of human existence and literally, everything and anything can have a bearing on the makeup of a translated text (TT). Every node in the translation chain, right from the very selection of the text to be translated to the micro-level textual aspects, can only be understood in relation to the entire context of translation where the translator becomes a central figure, though not an independent soul. In order to understand any translation endeavour, the various conditioning factors, the human and the non-human, and the different interdependencies have to be factored in that have a role in the whole gamut of the translation project.

As we live in an age of translation and Interpretation, it is hardly surprising for a field that began its career as a branch of Applied Linguistics to become an interdisciplinary area with multiple perspectives and newer paradigms emerging from different disciplinary and cultural contexts only to enlarge the frontiers of the field beyond one's imagination. This indeed marks the success story of the field of Translation Studies. 
Lakshmi Haribandi

\section{Appendix}

The paratexts that we find in both the translated texts give us valuable information to contextualise the texts and to understand various aspects that played a role in the making of the texts. Let us examine some of them here:

The TT-1

It has a one-page Preface (p. iii) by Meenakshi Mukherjee which explained the genesis of this work. According to her, the translators first prepared an extract of thousand words on this Telugu classical drama when she requested them for publication in her monthly column 'past Continuous' in the 'Literary Review' section of The Hindu. Later at the behest of The Book Review Literary Trust, which came forward to publish the entire text, the translators undertook the translation of the full text and completed it in record time.

It is also understood from this preface that The Book review Literary Trust wanted these translations made available with "some annotations and suitable critical commentary" (p. iii).

The main text is 273 pages that includes a glossary of two pages. The translators have reproduced all the paratexts that are there in the source text, viz. the Dedication, the Preface to The First Edition and the Preface to The Second Edition written by the source author in English in the source text itself. Additionally, the translators have added a Foreword of four pages and an Afterword of eight pages.

The Foreword introduces the author and his position in Telugu literary circles along with the drama under consideration and its significance and popularity among the Telugu people. Then the translators discuss a couple of challenges related to its translation. On the decisions that they have made in the process of translating the text, they state that they tried to remain close to the original rather than producing a smooth 
translation. They clearly state that their attempt was to strike a balance between "the two guiding principles of translation" fidelity to the original and readability in the target language (p.xiv).

The Afterword places the source text in its literary, social and cultural context and discusses the specific context and the purpose for which the drama was written and also the literary influences working on the writer. It also discusses the unique features of the text like its inter-textuality.

The glossary given at the end has 50 entries and provides an explanation for all the source words that have been retained in the translation

\section{The TT-2}

It is in 245 pages (online version) and includes besides the main text, the paratexts- Acknowledgements, Introduction, Notes on Translation and Transliteration at the beginning, and at the end, the following sections that run into 90 pages.

The Play in Context: A Second Look at Apparao's Kanyasulkam

Note on Names and Castes

On Kinship and Friendship

Performing Kanyasulkam

Card Game in Act Five, Scene Two

Guide to Pronunciation

Proper Names with Diacritics

\section{Notes}

This shows us the structure of the text. Two things can be inferred from the inclusion of all these paratexts: One, it is a fully annotated translation that gives all the ethnographic details regarding the source text and the source culture. The translation, in fact, acquires the nature of a scholarly or an 
academic translation that can be considered as a textbook fit to be included in the curriculum in any educational institution in India or outside India. Two, the location of the translation and its demands get highlighted in terms of production, circulation, and consumption of the translation.

\section{References}

Bourdieu, PIERRE. 1977. Outline of a Theory of Practice. Cambridge: Cambridge University Press.

Bourdieu, Pierre. 1994. The Field of Cultural Production. Cambridge: Cambridge University Press.

Chesterman, Andrew. 2009. The Name and Nature of Translator Studies. Hermes-Journal of Language and Communication Studies

42. https://tidsskrift.dk/her/article/download/96844/145601 (Accessed 7 September 2020).

Claudia V. Angelelli. 2014. The Sociological Turn in Translation and Interpretation Studies. Amsterdam/ Philadelphia: John Benjamins.

CRONIN, M. 2003. Translation and Globalization. London: Routledge.

Foglia, CECILIA. 2014. Tracking the Socio-graphical Trajectory of Marco Micone: A Sociology of Migration by Way of Translation. Translators Have Their Say? Translation and the Power of Agency. In Abdel Waheb Khalifa (ed.), Selected Papers of the CETRA Research Summer School 2013.

GENTZLER, E. 1993. Contemporary Translation Theories. New York: Routledge.

RAMANA Murthy, R. V. (ed.) 2012. Gurajada Sahitya Sarvasvam (Compendium of Literary Works of Gurajada). Hyderabad: Department of Culture, Government of Andhra Pradesh \& Telugu Akademi. 
C. Vijayasree. \& T. Vijay Kumar. 2002. Kanyasulkam. New Delhi: The Book Review Literary Trust.

Velcheru NARAYANA RAO. 2007. Girls for Sale: Kanyasulkam - A Play from Colonial India. Bloomington \& Indianapolis: Indiana University Press. https://www.amazon.com/Girls-Sale-KanyasulkamColonial.../0253219132 (Accessed 15 December 2019).

Hu Gengshen \& Youlan TaO. 2016. Eco-Translatology: A New Paradigm of Eco-Translation- A Comparative Study on Approaches to Translation Studies. 115-131. https://www.semanticscholar.org/.../Eco-

Translatology\%3A...New-

Paradigm .../88e2e0aa7814b1a1e059d79d54a795693effbd6 8 Online (Accessed 10 December 2020).

Hu Gengshen. 2020. Eco-Translatology: Towards an EcoParadigm of Translation Studies. Singapore: Springer.

Hu Gengshen. 2003. Translation as Adaptation and Selection. Perspectives: Studies in Translatology 4. 283-291. https://www.tandfonline.com/doi/abs/10.1080/0907676X.20 03.9961481 (Accessed 8 December 2020).

LEFEVERE, ANDREW. 1992. Translation-Culture/History: A Source Book. London/New York: Routledge.

Michaela Wolf \& AleXANDRA FuKARI (eds.). 2007. Constructing a Sociology of Translation. Amsterdam / Philadelphia: John Benjamins.

MundAY, JEREMY. 2000. Introducing Translation Studies: Theories and Applications. London: Routledge.

TOURY, GIDEON. 1980. In Search of a Theory of Translation. Tel Aviv: The Porter Institute for Poetics and Semiotics, Tel Aviv University.

TOURY, GIDEON. 1995. Descriptive Translation Studies and Beyond. Amsterdam/Philadelphia: John Benjamins. VENUTI, LAWRENCE. 1995. The Translator's Invisibility. London: Routledge. 
Lakshmi Haribandi

Venuti, Lawrence (ed.). 2000. The Translation Studies Reader. London: Routledge.

***

\section{Cite This Work:}

HARIBANDI, LAKSHMI. 2021. The Ecology of Translation: A Case Study of Two Different Translations of Kanyasulkam in English. Translation Today, Vol. 15(1). 1-28.

DOI:10.46623/tt/2021.15.1.ar1 